\title{
Gas Chromatography-Mass Spectroscopy Study of tert-Butylarsine Stability and Purification
}

M.E. Bartram, ${ }^{*}$ W.G. Breiland, and L.A. Bruskas

Chemical Processing Sciences Department,

Sandia National Laboratory, Albuquerque, NM 87185-0601

K.P. Killeen

Hewlett-Packard

Palo Alto, $C A$

(For submission to J. Cryst. Growth)

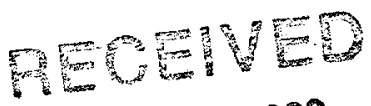

AUS $1: 1999$

OSTI

We have used GCMS (gas chromatography-mass spectroscopy) to study the decomposition of TBA (tert-butylarsine, $\mathrm{H}_{2} \mathrm{AsC}\left(\mathrm{CH}_{3}\right)_{3}$ ) in storage containers at room temperature. Over a four week period, $0.1 \%$ to $1 \%$ of the TBA decomposed to arsine and isobutane in a stainless steel bottle. Several freezethaw purification schemes were tested. Use of a liquid nitrogen bath left a substantial amount of arsine and isobutane in the bottle; while an ice water bath removed all of the arsine but left residual isobutane. Evacuation of the storage container at room temperature proved to be an effective way to remove both arsine and isobutane to below the GCMS detection limits. However, this approach did lead to significant TBA loss. Storing TBA in a teflon-lined bottle and in a high surface-to-volume stainless steel bottle did not change the decomposition rate measurably, suggesting that stainless steel surfaces do not promote TBA decomposition.

*Author to whom correspondence should be addressed. 


\section{DISCLAIMER}

This report was prepared as an account of work sponsored by an agency of the United States Government. Neither the United States Government nor any agency thereof, nor any of their employees, make any warranty, express or implied, or assumes any legal liability or responsibility for the accuracy, completeness, or usefulness of any information, apparatus, product, or process disclosed, or represents that its use would not infringe privately owned rights. Reference herein to any specific commercial product, process, or service by trade name, trademark, manufacturer, or otherwise does not necessarily constitute or imply its endorsement, recommendation, or favoring by the United States Government or any agency thereof. The views and opinions of authors expressed herein do not necessarily state or reflect those of the United States Government or any agency thereof. 


\section{DISCLAIMER}

Portions of this document may be illegible in electronic image products. Images are produced from the best available original document. 
TBA (tert-butylarsine, $\mathrm{H}_{2} \mathrm{AsC}\left(\mathrm{CH}_{3}\right)_{3}$ ) has been demonstrated to be an effective arsenic precursor for the deposition of compound semiconductors such as GaAs by MOCVD (metal organic chemical vapor deposition). TBA is used as a liquid (bubbler) source in MOCVD and is a less toxic alternative to the more commonly used gaseous arsine $\left(\mathrm{AsH}_{3}\right)$. Materials and device performance using TBA have in many cases equaled or surpassed those using arsine. This includes the first observation of fractional quantum Hall behavior in a two dimensional electron gas structure grown by MOCVD. (1)

Despite the beneficial characteristics, the use of TBA in our laboratories has revealed some inconsistent behavior. Small pressure rises have been observed in the TBA bubbler sources when left unused over a period of many days. Measurements of the TBA partial pressure using UV absorption revealed that new absorption peaks could be observed after storage. The features of the absorption profile were insufficient to ascribe to a specific chemical species. Attempts to remove the gaseous impurities with liquid nitrogen freeze-pump-thaw techniques had limited success. Unfortunately, there is no published information on the room temperature decomposition of TBA. . In this paper, we present a series of GCMS (gas chromatography-mass spectroscopy) analyses designed to determine the stability of TBA and identify its decomposition products in storage containers. The GCMS is also used to evaluate several methods for in-situ purification of TBA.

\section{Experimental}

The experimental apparatus consisted of a Hewlett-Packard GCMS (a 5890 Series II "Plus" GC and a 5972 Series MS). The chromatographic column was a $60 \mathrm{~m}$ long, $0.25 \mathrm{~mm}$ internal diameter HP-1 with a $0.25 \mu \mathrm{m}$ thick, $100 \%$ dimethyl-polysiloxane (non-polar) stationary phase. Temperatures of the column, injection valve, injection head, and mass spectrometer interface capillary were held at $40^{\circ} \mathrm{C}$ during the GCMS analyses. Samples were taken from the TBA bottle at room temperature using a stainless steel sampling manifold and an injection valve.

TBA (>99\%) was obtained from Air Products. Approximately $2 \mathrm{~g}$ were transferred from the original bubbler to a $25 \mathrm{cc}$ stainless steel bottle (referred to as the "normal" or "normal surface area" bottle) via a stainless steel manifold by freeze-trapping with liquid nitrogen. Isobutane (99.99\%) and isobutylene (99.99\%), used in the reference studies, were obtained from Matheson.

\section{Results and Discussion}

The total ion chromatogram (integrated mass spectral ion signal) for the GCMS analysis of TBA stored in a stainless steel bottle for four weeks at room temperature is shown at the bottom of figure 1 as the "normal bottle". (The TBA was first purified by the room temperature method described in the next sub-section.) Each of the three peaks is associated with only one species, since the mass spectral cracking patterns have identical relative intensities throughout any one peak. Representative mass spectra are shown in figure 2 with their chromatographic retention times (tR) and are in good agreement with published mass spectra for arsine,(2) isobutane,(2) and TBA.(3) In addition, the chromatographic 
peak shapes in figure 1 clearly indicate that arsine and isobutane are not the result of decomposition of TBA on the column since they are well-separated from the TBA peak and they do not have extended trailing edges. (The nitrogen peak in the spectrum is used for calibration purposes.) These results also indicate that disproportionation products such as higher-order alkyl arsine species are not present in the TBA bottle since the high end of our scan range $(220 \mathrm{~m} / \mathrm{z})$ would have detected portions of their cracking patterns above the highest $\mathrm{m} / \mathrm{z}$ of TBA. Similarly, the low end of the scan range $(1.2 \mathrm{~m} / \mathrm{z})$ allows us to conclude that TBA decomposition does not lead to the formation of $\mathrm{H}_{2}$.

The benefits of pumping on TBA at room temperature $\left(27^{\circ} \mathrm{C}\right)$ are demonstrated by the absence of the arsine and isobutane peaks in the room temperature chromatogram in figure 1. Clearly, the arsine and isobutane levels are reduced to below the GCMS detection limit. Unfortunately, the 10s pumping time necessary to accomplish this also removed about half of the $2 \mathrm{~g}$ of TBA in the bottle. Although it is not conclusive that a $50 \%$ loss of TBA is required to remove all of the arsine and isobutane, the potential for a significant loss of TBA occurring in a very short time must be considered carefully before using this method.

Precursor bubblers are often placed in liquid nitrogen $\left(-196^{\circ} \mathrm{C}\right)$ while pumping to selectively remove volatile impurities. However, our results indicate that this approach has limited effectiveness, since the $-196^{\circ} \mathrm{C}$ chromatogram in figure 1 shows that neither arsine nor isobutane are completely removed by pumping for $10 \mathrm{~s}$ while immersed in liquid nitrogen. Repeating the procedure did not provide significant improvement.

Table 1. Melting and boiling points for TBA and its decomposition products. Melting point $/{ }^{\circ} \mathrm{C} \quad$ Boiling point $/{ }^{\circ} \mathrm{C}$

$\begin{array}{lrrr}\text { Isobutane } & -159 & -12 & (4) \\ \text { Arsine } & -116 & -55 & (4) \\ \text { TBA } & -1 & 69 & (5) \\ \end{array}$

The ineffectiveness of pumping at liquid nitrogen temperature is not surprising when the melting and boiling points of these species are considered. As shown by the melting points in Table 1, arsine and isobutane, as well as TBA are solids at $-196^{\circ} \mathrm{C}$. The optimal bubbler purification temperature might be between $-12^{\circ}$ and $-1{ }^{\circ} \mathrm{C}$, since this would solidify TBA without liruefying isobutane. For our experiment, $0^{\circ} \mathrm{C}$ was chosen because of the convenience of using ice water. The results for trying this approach are given in figure 1 as the $0^{\circ} \mathrm{C}$ chromatogram. Arsine is removed completely, but isobutane remains at a detectable level after pumping for $10 \mathrm{~s}$.

To better understand decomposition in storage containers, 100 Tor TBA was stored in a teflonlined stainless steel bottle and a high surface-to-volume stainless steel bottle at room temperature. Use of this pressure and temperature ensured that liquid TBA was not present.(5) The latter bottle had a surfaceto-volume ratio that was a factor of ten greater than both the teflon-lined bottle and the normal bottle described above. After 12 weeks, isobutane could barely be detected in either the high surface area or 
teflon-lined bottles. Coincidentally, their chromatograms were nearly identical to the $0^{\circ} \mathrm{C}$ spectrum in figure 1. It is likely that arsine was also formed, but at a level below the GCMS detection limit.

The amount of isobutane (a direct measure of TBA decomposition) was much less than that observed in the presence of liquid TBA. However, the total amount of TBA decomposition in each of the three bottles (considering the liquid phase in the normal bottle) was between $0.1 \%$ and $1 \%$. Although the precision was limited by having to use the calibration curve near zero, direct comparison of -isobutane formation suggests that the high surface area stainless steel bottle did not enhance the decomposition rate relative to the teflon-lined bottle.

Although our results show that arsine and isobutane are the only volatile products formed by TBA decomposition at room temperature, at least one additional species must be involved in the decomposition reaction to achieve mass balance. Since isobutylene was not observed, the participation of an additional hydrogen source in the reaction such as an arsenic hydride may be likely. We suggest that reactions I and II are involved in the TBA decomposition to yield reaction III overall. These types of reactions would lead to the formation of solid arsenic. Of course, neither solid arsenic nor short-lived

Reaction I $2 \mathrm{H}_{2} \mathrm{AsC}\left(\mathrm{CH}_{3}\right)_{3}$

Reaction II $\mathrm{H}_{2} \mathrm{AsC}\left(\mathrm{CH}_{3}\right)_{3}+2:: \mathrm{As}-\mathrm{H}$

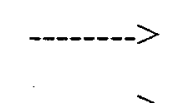

- $---->>$
$2 \mathrm{HC}\left(\mathrm{CH}_{3}\right)_{3}+2:: \mathrm{As}-\mathrm{H}$

$\mathrm{HC}\left(\mathrm{CH}_{3}\right)_{3}+2 \mathrm{As}_{\mathrm{S}}+\mathrm{AsH}_{3}$

Overall:

Reaction III $3 \mathrm{H}_{2} \mathrm{AsC}\left(\mathrm{CH}_{3}\right)_{3}$

$-3 \mathrm{HC}_{3}\left(\mathrm{CH}_{3}\right)_{3}+2 \mathrm{As}_{\mathrm{S}}+\mathrm{AsH}_{3}$

arsenic hydrides as in reactions I and II would be observable with GCMS. In principle, arsenic hydride surface species could be used in place of ::As-H. However, the involvement of surface hydrides in the reaction is unlikely since TBA decomposition was not enhanced in the high surface area bottle.

It must be emphasized that our GCMS results can neither confirm nor exclude the stoichiometries inferred by reaction III or similar possibilities. This example is intended only to be illustrative of a general suggestion that is consistent with the gas-phase species detected in the TBA bottle. In comparison with previous high-temperature decomposition studies $(3,6-8)$ in which both isobutene and isobutane can be formed depending on the pressure, it would appear that the only reaction pathway available at room temperature produces isobutane.

In summary, an effective GCMS method has been developed for the analysis of TBA and its decomposition products. The decomposition products observed were arsine and isobutane. The formation of these species with consideration of mass balance implies that the reaction also produces solid arsenic. TBA decomposition rates were not enhanced by increasing the surface-to-volume ratio of the stainless steel container. A teflon lined vessel did not decrease decomposition. The upper limit on TBA decomposition may be as high at $1 \%$ over a 4 week period at room temperature. This indicates that TBA has a finite "shelf-life" and that steps must be taken to reduce the temperature of the bubbler if this 
decomposition rate is unacceptable. Evaluation of purification schemes revealed that room temperature evacuation removes decomposition products quite well but at a cost of a substantial amount of TBA. Evacuation at $0^{\circ} \mathrm{C}$ may be preferable if a low partial pressure of isobutane is acceptable.

\section{Acknowledgments}

This work was performed at Sandia National Laboratories under DOE contract DE-AC04 94AL85000.

Sandia is a multiprogram laboratory operated by Sandia Corporation. a Lockheed Martin Company. for the

Figure captions

United States Department of Energy under contract DE-AC04-9 \&AL 85000 .

Fig. 1 Total ion chromatograms (integrated mass spectral ion signal) of gas-phase samples taken from the normal surface area TBA bottle after four weeks and after attempting three different purification procedures. Temperatures used for purification are given next to the chromatograms. All samples were taken with the bottle at room temperature $\left(27^{\circ} \mathrm{C}\right)$. The chromatograms of the samples taken from the teflon-lined and high surface area bottles, coincidentally, were nearly identical to the $0^{\circ} \mathrm{C}$ chromatogram. Mass spectra associated with the peaks are shown in figure 2 . Nitrogen was used for calibration purposes.

Fig. 2 Mass spectra obtained for isobutane, arsine, and TBA from a mixture separated with gas chromatography. Backgrounds have been subtracted. Retention times (tR) refer to the peak locations in the chromatograms in figure 1.

\section{References}

1. H.C. Chui, B.E. Hammons, N.E. Harff, J.A. Simmons, and M.E. Sherwin, Appl. Phys. Let., G8, $208(1996)$.

2. $\quad$ S.R. Heller and G.W.A. Milne, EPA/NIH Mass Spectral Data Base, Gaithersburg: U.S. Department of Commerce, 1978.

3. C.A. Larsen, N.I. Buchan, S.H. Le, and G.B. Stringfellow, J. of Cryst. Growth, 94, 663 (1989).

4. CRC Handbook of Chemistry and Physics, 60th ed. Boca Raton: CRC Press, 1979.

5. $\quad$ Gases Group Materials Safety Data Sheet, Air Products, MSDS 4T01, 1993.

6. R.H. Marking, W.L. Gladfelter, and K.F. Jensen, Chem. Mater., 2, 499 (1990).

7. D.F. Foster, C. Glidewell, and D.J. Cole-Hamilton, J. Electronic Mater., 23, 69 (1994).

8. P.W. Lee, T.R. Omstead, D.R. McKenna, and K.F. Jensen, J. of Cryst. Growth, 93, 134 (1988). 


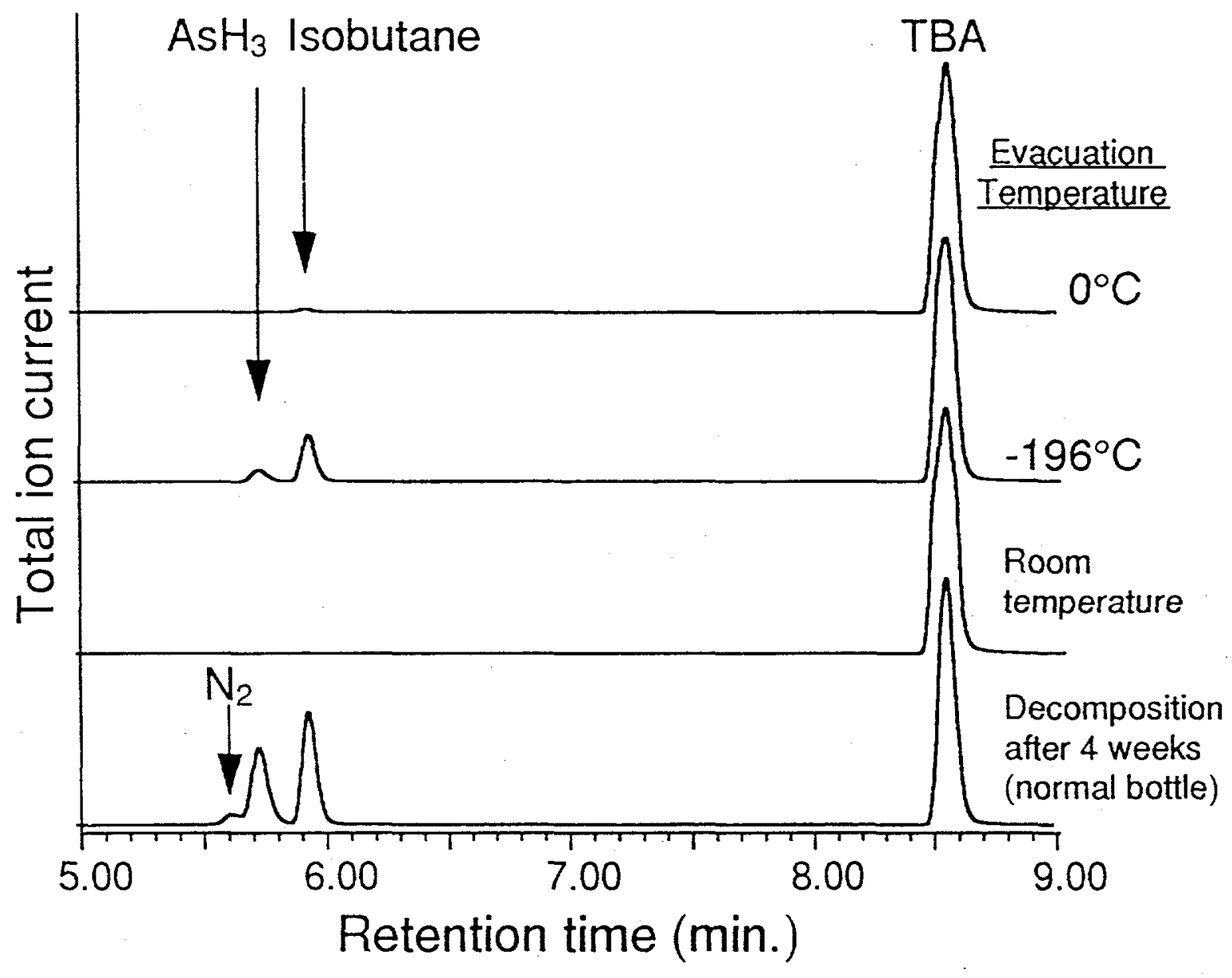

Figure 1.

(Bartram et al.) 


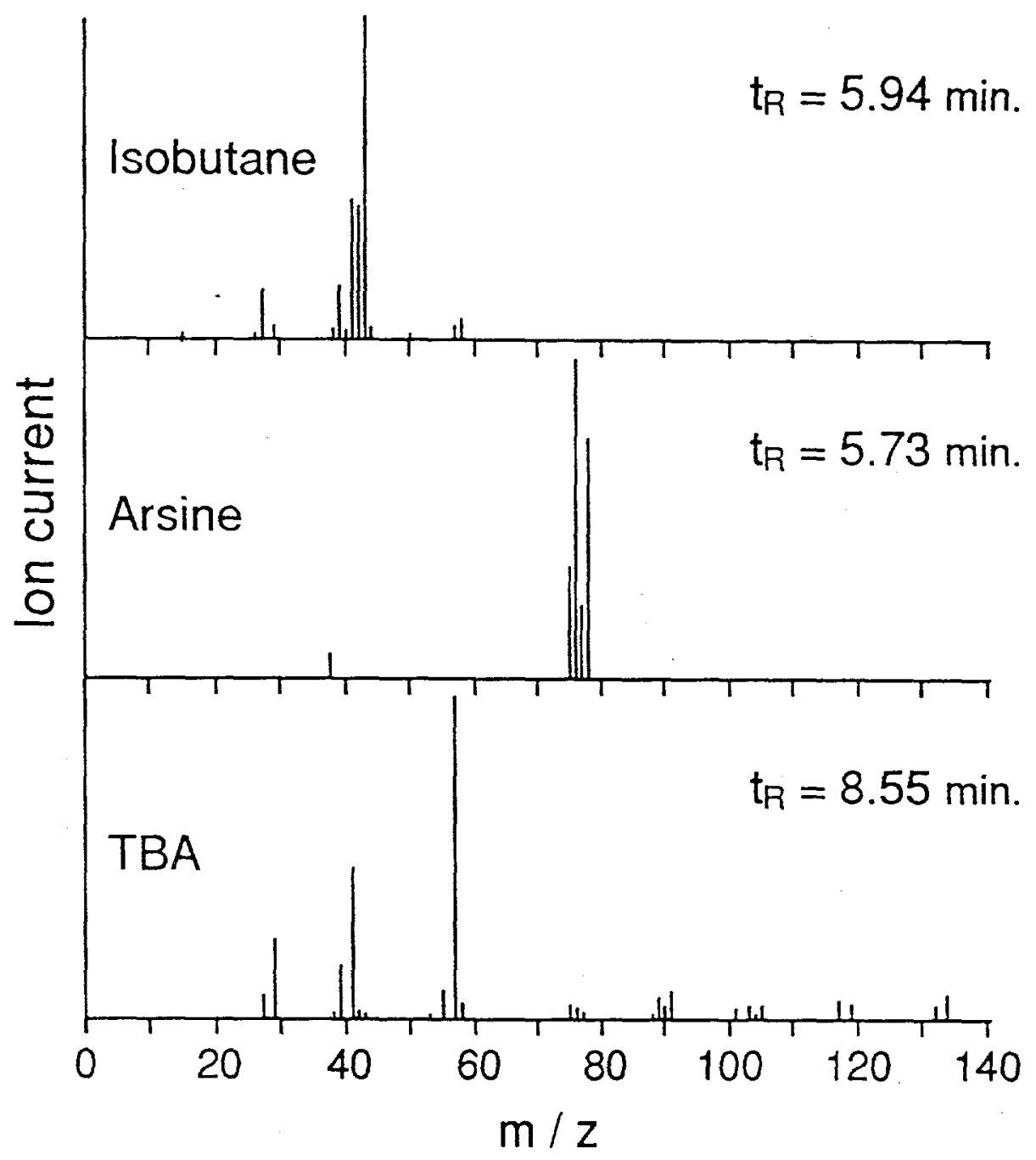

Figure 2.

(Bartram et al.) 